\title{
Programa de Capacitação Docente em Administração (PCDA)
}

Antônio Freitas*

Tânia Fischer**

\section{Introdução}

Melhorar o ensino de administração é a meta principal do Programa de Capacitação Docente em Administração (PCDA).

O PCDA é a expressão de uma política de indução e fomento à melhoria do ensino de administração, sendo inovador em seus propósitos e formato. Compreende projetos e atividades que articulam graduação e pósgraduação (stricto sensu e lato sensu), pesquisa, ensino e difusão, sendo um programa de apoio à formação e requalificação docente.

O programa está respaldado pelo IV Plano Nacional de Pós-Graduação e se constitui na resposta de área à política de integração entre a pós-graduação e a graduação. Foi compartilhado por cinco instituições na fase de implantação, com 20 novas adesões, e será objeto de monitoramento e avaliação pela diretoria de avaliação da Anpad.

\section{Caracterização}

O PCDA compreende atividades de ensino, pesquisa e difusão.

a) como um programa de educação continuada para qualificação e requalificação de professores de administração, o PCDA é por constituído por:

- Mestrado em Ensino de Administração (interinstitucionais), com módulos didáticos;

- orientação de mestrados e doutorados à docência; por meio de disciplinas e atividades de formação docente, integrantes dos currículos desses cursos;

- Curso de Especialização Docente, com ênfase em áreas de conteúdo e didática de administração;

- oficinas de Capacitação Docente, com simulação de ensino e microexperiências orientadas por modelo de competência docente;

- estágios docentes em escolas de administração.

b) como indutor de pesquisa, o PCDA estimula uma rede de pesquisas sobre ensino e aprendizagem em administração e tem como produtos possíveis:

- estudos configuracionais da área;

- pesquisas sobre inovações e desenvolvimento curricular;

Ph.D. pela North Carolina State University- EUA. Professor, Chefe de Centro da Graduação (EBAPE) e Diretor Executivo do IDE. Endereço: Praia de Botafogo, 190 - sala 532 - Botafogo - Rio de Janeiro - RJ - CEP 22250-900. E-mail: afreitas@ fgv.br.

* Doutora em Administração. Professora Titular da UFBA - Coordenadora do Centro Internacional de Gestão Social para o Desenvolvimento. Endereço: Universidade Federal da Bahia - Escola de Administração - NPGA - Av. Reitor Miguel Calmon s/no- 3o andar - Vale do Canela - 40110- 100. E- mail: nepol@ ufba.br.

**** Artigo recebido em outubro de 2006 e aceito para publicação em outubro de 2006. 
- formas de aprendizagem e diversidade do alunado;

- perfis de professor e desenvolvimento de competências docente;

- seleção de conteúdos e organização de ensino (projetos pedagógicos);

- tecnologias de ensino presenciais e a distância;

- construção de materiais e recursos de ensino (casos) e uso dos mesmos;

- uso de recursos estéticos em ensino, como cinema, teatro, fotografia, música etc.

c) o PCDA é também articulador de atividades de extensão, como eventos temáticos, e de publicações, como a Revista de Ensino de Administração, em estudo.

\section{Antecedentes}

O PCDA foi implantado na abertura do Enanpad, em Curitiba, no dia 23-9- 2004. Em 14-10-2004, o PCDA foi divulgado em fórum da Angrad, realizado em Salvador, com a presença do presidente da Angrad, diretores científicos da Anpad e Angrad e coordenadores do PCDA. Em 29 de outubro, a reunião de representantes das instituições-pólo, mais a diretoria de avaliação da Anpad eleita para o biênio 2005/2006, deliberou sobre a operacionalização do programa. Em 2005 e 2006, quatro instituições desenvolveram atividades de ensino, pesquisa e difusão.

Em agosto de 2006, na reunião sobre políticas e diretrizes sobre ensino da área, constatou-se que as instituições estão desenvolvendo planos diferenciados, com ênfase em:

- constituição de grupos e linhas de pesquisa em ensino;

- criação de alternativas de capacitação docente nos cursos;

- construção de projetos de mestrado no ensino de administração;

- propostas de cursos de especialização, presenciais e a distância.

Está em discussão um evento no âmbito do Enanpad e a Revista de Ensino de Administração. Propõe-se, no momento, a inclusão das atividades do PCDA na avaliação da Capes; ou seja, que a formação de professores e a preocupação com a pesquisa sobre ensino e aprendizagem, bem como atividades de difusão, sejam considerados nos quesitos e critérios de avaliação dos cursos de pós-graduação na área.

Os programas participantes do PCDA constituem uma rede e já se definem parcerias interinstitucionais para o desenvolvimento de projeto. 